\title{
A questão da relevância nos estudos dos movimentos sociais
}

The question of relevance in social movement studies

La question de l'impact dans les études des mouvements sociaux

Dick Flacks

Tradutor. João Paulo Moreira

\section{(2) OpenEdition}

\section{Journals}

Edição electrónica

URL: http://journals.openedition.org/rccs/980

DOI: $10.4000 /$ rccs.980

ISSN: 2182-7435

Editora

Centro de Estudos Sociais da Universidade de Coimbra

\section{Edição impressa}

Data de publição: 1 Outubro 2005

Paginação: 45-66

ISSN: 0254-1106

\section{Refêrencia eletrónica}

Dick Flacks, «A questão da relevância nos estudos dos movimentos sociais », Revista Crítica de Ciências Sociais [Online], 72 | 2005, colocado online no dia 01 outubro 2012, criado a 03 maio 2019 URL : http://journals.openedition.org/rccs/980 ; DOI : 10.4000/rccs.980

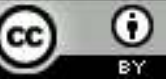




\section{DICK FLACKS}

\section{A questão da relevância nos estudos dos movimentos sociais}

A colaboração entre Charles Tilly, Sidney Tarrow e Doug McAdam traduziu-se num quadro conceptual que hoje domina os estudos dos movimentos sociais. O trabalho destes autores teve a utilidade de dirigir a atenção para as determinações estruturais das acções de protesto, ao acentuar as oportunidades externas, as ameaças e os constrangimentos que explicam a emergência e evolução dos movimentos. Sucede, no entanto, que os estudos dos movimentos sociais se foram tornando cada vez mais "académicos", apontando sobretudo para o apuramento dos conceitos e o testar das hipóteses. Nesse sentido, o trabalho realizado nesta área não só tem perdido relevância social como tem vindo a descurar questões intelectuais que são fundamentais. Entre estas contam-se os esforços no sentido de compreender as origens do poder dos movimentos e da motivação dos activistas. Uma forma de restaurar aquilo que é relevante e substancial será fazer com que os académicos vocacionados para a questão dos movimentos retomem o diálogo com os activistas desses mesmos movimentos.

Passaram já quase 50 anos desde a publicação do livro Sociological Imagination, de C. Wright Mills. Na obra, o autor sem dúvida presta homenagem ao trabalho intelectual por aquilo que ele é. Mas Mills queria que os intelectuais entendessem o fundo moral da sua vocação: nada menos do que defender a capacidade que o ser humano tem para a razão e para a liberdade. O contributo dos sociólogos para essa defesa consistiria em ajudar as pessoas a entender que os seus problemas, sendo pessoais na aparência, são, em potência, grandes questões sociais; em levar as pessoas a entender que as suas vidas e o meio em que se movem se encontram engastados em estruturas sociais e na História.

Assim, a investigação do social deveria ter por motivação maior, não a necessidade de testar e apurar teorias, mas sim a humana necessidade de conhecer e agir:

Seja na trajectória individual de uma pessoa singular, seja na história de uma dada sociedade, a tarefa social da razão consiste em formular escolhas, por forma a alargar o leque das decisões humanas no fazer da História. O futuro dos assuntos 
humanos não se resume a uma qualquer teia de variáveis que é preciso prever. O futuro é o que está por decidir - dentro, obviamente, dos limites da possibilidade histórica. Mas essa possibilidade não é algo de fixo... Sob que condições querem os homens ser livres e capazes de agir livremente? Sob que condições estão dispostos e aptos a carregar o fardo que a liberdade sempre traz consigo e a encará-lo menos como um fardo do que como autotransformações alegremente assumidas? (Mills, 2000: 174-175)

\section{Se Mills hoje fosse vivo, dava voltas no túmulo}

Li The Sociological Imagination em 1960, quando, ainda jovem, estudava Psicologia Social na universidade, em Ann Arbor. Dois anos depois encontrava-me em Port Huron, também no Michigan, integrado num grupo de várias dezenas de jovens, muitos dos quais vindos da linha da frente da luta pelos direitos cívicos, no Sul. Estávamos ali com a finalidade de redigir um manifesto para uma geração nova e fundar uma organização denominada Students for a Democratic Society (SDS - Estudantes para uma Sociedade Democrática), destinada a representar uma Nova Esquerda que então emergia. A visão e a linguagem de Mills influenciaram fortemente aquilo que viria a ser a Declaração de Port Huron. Tal declaração corporizava a esperança e a reivindicação de que os activistas dos movimentos então emergentes fossem capazes de estabelecer ligação com os recursos intelectuais e o espaço livre da universidade. Ela via na universidade um novo centro de poder social da economia política emergente. Ainda segundo esta declaração, a crescente relevância social da universidade, a sua centralidade na produção de conhecimento, e a sua relativa abertura ao debate político livre "fazem dela uma base e um agente potenciais num movimento apontado à transformação social".

Para alguém que, como eu, se deixou imbuir do espírito e da visão de C. Wright Mills e de Port Huron e que continuou no meio universitário ao longo de todos estes anos, é cada vez mais desanimador assistir ao estado geral dos estudos dos movimentos sociais na sociologia norte-americana. Julgo que, em comparação com a década de 1960, é hoje muito maior o envolvimento dos sociólogos nas acções dos movimentos sociais e nas organizações e redes de activistas. Muitos de nós procuram ser activos tanto dentro como fora do espaço da universidade. Muitos são, também, aqueles que prestam um serviço útil a projectos, lançando mão das capacidades e dos recursos que nos são próprios e facilitando, assim, o trabalho dos movimentos. O que aqui pretendo não é salientar o problema do isolamento dos estudiosos dos movimentos sociais na sua torre de marfim, 
mas antes perguntar se a substância do nosso sistemático teorizar e de toda a nossa investigação terá alguma ligação com o trabalho levado a cabo pelos activistas.

Estudar os movimentos sociais é, nos termos propostos por Mills, perguntar em que condições é que o ser humano se torna capaz de querer a liberdade e de agir livremente. O esforço no sentido de estudar e esclarecer teoricamente estas questões é essencial para aqueles que se acham envolvidos nas lutas sociais, ajudando a dotá-los do saber teórico-prático necessário a uma acção verdadeiramente eficaz.

A investigação e a teorização sobre os movimentos sociais tiveram um surto muitíssimo grande ao longo dos últimos vinte anos. Não me parece que uma grande parte desse trabalho, e em particular o trabalho hoje considerado de referência neste campo, nos forneça o esclarecimento a que acima aludi. Pelo contrário, o campo está a assemelhar-se àquele misto de teorização inflacionada e de empirismo abstracto que, nos finais da década de 1950, Mills considerava estar a dominar a sociologia no seu conjunto.

\section{O paradigma dominante}

A grande novidade nos estudos dos movimentos sociais nos Estados Unidos da América ao longo destes últimos vinte anos tem sido o esforço concertado, encabeçado por Charles Tilly, Doug McAdam e Sidney Tarrow, no sentido de formular uma estrutura conceptual para este campo. Dotados de financiamentos e tendo por base o Palo Center for Advanced Study in Behavioral Science, estes autores conseguiram identificar toda uma rede de estudiosos e um mecanismo conceptual que são hoje a principal força por trás dos estudos dos movimentos sociais. Dos seus esforços resultou uma série de compilações de trabalhos de investigação que visam ilustrar e apontar o caminho para linhas de pesquisa correctas. Além disso, estes três principais responsáveis publicaram recentemente um livro que traça uma estrutura teórica para o domínio daquilo a que chamam "políticas de contestação" (contentious politics), expressão que alude a um dos principais objectivos do seu projecto: articular num quadro teórico único a teoria e a investigação relativas a um amplo leque de dinâmicas sociais, incluindo, por exemplo, os movimentos sociais, as revoluções, os conflitos étnicos e religiosos, e ainda os conflitos industriais.

Conseguir essa articulação parece ser um objectivo bastante válido. É, com efeito, estranho que os estudos sobre os movimentos e sobre a problemática da revolução tenham enveredado por linhas de investigação separadas, com pouca fertilização recíproca, e que os esforços para com- 
preender os nacionalismos religiosos e as rivalidades étnicas pareçam intelectualmente distantes dos estudos relativos a outros tipos de mobilização popular. Assim, parece fazer sentido o projecto daqueles autores com vista a conseguir articular a análise teórica destas formas de acção colectiva, tal como faz sentido a sua intenção, relacionada com esta, de "questionar a fronteira entre a política institucional e não-institucional” (McAdam, Tarrow e Tilly, 2001: 2).

O objectivo geral que os move consiste em encontrar regularidades e variações sistemáticas entre todos os tipos de políticas de contestação, definidas como "uma interacção episódica e colectiva entre entidades reivindicativas e os respectivos oponentes sempre que a) pelo menos o governo de um Estado é parte reivindicativa ou objecto da reivindicação ou faz parte da própria reivindicação, e b) sempre que as reivindicações, se satisfeitas, afectem os interesses de pelo menos uma das entidades reivindicativas" (McAdam, Tarrow e Tilly, 2001: 5). Os membros do grupo TMT ${ }^{1}$ procedem a uma outra especificação importante dos interesses que os norteiam quando falam de "luta constituinte". Luta constituída significa os tipos de conflito político que ocorrem entre autores políticos já firmados, que lançam mão de meios políticos igualmente já estabelecidos. Quanto à luta constituinte, refere-se a conflitos políticos em que as reivindicações partem de actores anteriormente excluídos ou novos, normalmente com recurso a formas de acção igualmente novas e, muitas vezes, não autorizadas. Assim, os movimentos sociais (juntamente com fenómenos como a revolução, a "democratização", as ondas grevistas e os nacionalismos) são exemplos primaciais de luta constituinte.

Julgo ser consensual, para o campo aqui em presença, a seguinte definição de movimentos sociais: trata-se de esforços colectivos com alguma duração e um certo grau de organização, que utilizam métodos não institucionalizados para provocar a mudança social. A abordagem de TMT confere especial ênfase aos movimentos cujos objectivos não só têm em mira a mudança ("reivindicações"), como possuem uma clara dimensão política (isto é, implicam, de algum modo, o Estado). Adiante, debruçar-me-ei em pormenor sobre os modos como uma definição dos movimentos tão explicitamente "política" impede uma compreensão cabal.

Os contributos de TMT contam-se entre os mais importantes para o estudo sistemático dos movimentos sociais desde há décadas. As actuais tentativas de codificação por parte destes autores representam o culminar

\footnotetext{
${ }^{1}$ Doravante usarei a sigla TMT para designar Tilly, McAdam e Tarrow, assim como o projecto de que são responsáveis.
} 
de esforços por si anteriormente empreendidos a título individual. A partir da década de 1970, e a par de outros autores, eles vieram pôr em causa interpretações até aí dominantes relativas ao fenómeno do protesto e dos movimentos, ajudando assim a imprimir um novo rumo aos estudos dos movimentos sociais.

O tipo de pensamento que vieram contestar tendia a ver os protestos colectivos como uma forma de desvio ou patologia. O estudo clássico dos movimentos sociais tinha as suas raízes nas noções de "psicologia das multidões". As interpretações clássicas viam as acções de massas como expressão do colapso da sociedade e da anomia social; era frequente considerar-se que os seus dirigentes agiam levados por impulsos psíquicos inconscientes, e que os que nelas participavam iam atrás de uma ideologia irracional. $\mathrm{Na}$ década de 1960, era frequente os meios de comunicação retratarem o grande surto de movimentos recorrendo a estes estereótipos clássicos, mas aqueles sociólogos que ao atingirem a maioridade eram participantes ou simpatizantes dos movimentos dos anos 60 não estavam dispostos a aceitar esse tipo de caracterização.

A nova visão dos movimentos sociais pós-anos sessenta passava por uma ênfase nos movimentos enquanto "política por outros meios", encarando-os como esforços colectivos no sentido da prossecução de determinados interesses através de estratégias inteligíveis e apontando a objectivos racionais. Para compreender os movimentos não era preciso fazer a psicanálise dos participantes, mas antes que se explicassem os modos como o surgimento e evolução de um dado movimento estavam relacionados com as oportunidades, as ameaças e os recursos disponíveis para atingir os respectivos fins. Afinal, a participação em movimentos explicava-se melhor através da análise dos modos como os participantes se achavam inseridos nas comunidades e redes do que com base no pressuposto de que se tratava de gente desenraizada ou socialmente alienada. Em vez de ver os movimentos como forças irracionais ou destrutivas, era mais fiel à verdade histórica reconhecer o seu papel constitutivo no moldar das sociedades modernas.

Muitos daqueles que se dedicaram ao estudo dos movimentos sociais nas décadas de 1960 e 1970 eram, eles próprios, politicamente activos. A impressão que retive desse período foi que esses estudiosos acreditavam que o seu trabalho devia contribuir para os esforços no sentido de alcançar a igualdade social, a democracia, e "objectivos emancipatórios". A seguir aos anos 60 havia uma consciência generalizada de que, pelo menos nos anos do pós-guerra, a sociologia estivera, em grande medida, ao serviço do controlo social. O slogan do "movimento de libertação da sociologia" - um comício radical realizado nas reuniões da ASA (Associação Americana de Sociolo- 
gia), em 1968 - era "conhecimento para quem"? Foi viva a discussão, em todas as disciplinas, sobre a função social e o conteúdo moral das ciências sociais. O desafio lançado por Mills no início dos anos 60 tornar-se-ia no projecto consciente da nova geração, no refluxo da década.

Desse período resultou uma espécie de consenso segundo o qual, caso a investigação se centrasse na realidade dos mais fracos e desfavorecidos, os respectivos autores estavam eticamente obrigados a deixá-los utilizar os resultados da pesquisa; e ainda segundo o qual havia que estar sensibilizado para os diversos modos como o trabalho realizado podia ser aproveitado para perpetuar os arranjos sociais já estabelecidos e reprimir uma eventual oposição. Deste modo, o estudo dos movimentos sociais deveria facultar aos activistas desses movimentos recursos intelectuais a que, de outro modo, não teriam fácil acesso. Tal estudo seria de molde a permitir uma melhor avaliação de quais as estratégias e tácticas mais eficazes, poderia ajudar os activistas a situar os respectivos esforços em termos históricos e estruturais, e poderia ajudar os movimentos a melhorar os seus esforços no sentido de comunicar com os grupos ou comunidades envolventes e com potenciais simpatizantes, bem como a interpretar as acções dos adversários, a identificar as oportunidades de aumentar a pressão, etc.

Ao acentuar os aspectos da "mobilização de recursos", da "oportunidade política", e do "enquadramento", o novo paradigma conferia o primado à questão da estratégia. De facto, o trabalho produzido nessa linha revelou-se de uma utilidade imediata para os activistas, já que alguma da investigação e da produção teórica levada a cabo por sociólogos oriundos da academia cedo se reflectiu nos programas de formação e nos manuais dos movimentos. ${ }^{2}$ Para quem estava empenhado nos estudos dos movimentos sociais, era possível imaginar que a sua actividade lectiva, a actividade de consultadoria, a participação directa e ainda todo o esforço posto na investigação se podia revelar de alguma relevância para as práticas dos activistas políticos e para o seu melhor esclarecimento. ${ }^{3}$

\footnotetext{
${ }^{2}$ Gamson (1990), Piven e Cloward (1979), e Ryan (1991) são exemplos desse tipo de trabalho.

${ }^{3} \mathrm{Na}$ verdade, os esforços empreendidos após a década de 1960 no sentido de associar os dois papéis, o do académico e o do activista, já tinham atrás de si uma longa tradição. Nos inícios do século XX, John Dewey, George Herbert Mead e outros vultos da Universidade de Chicago despenderam muito do seu tempo a ajudar a desenvolver o movimento operário (e ao longo de toda a sua vida, Dewey assumiria papéis de direcção no que se refere à organização sindical dos professores e ao activismo político de cariz social democrático). As tentativas de Paul Lazarsfeld para realizar investigação no domínio dos inquéritos tiveram origem no seu interesse em ajudar o Partido Social Democrático da Áustria a avaliar os respectivos índices de aceitação política. Finalmente, são óbvias as inter-relações entre a investigação académica e o activismo nas vidas de figuras como W. E. B. Dubois e Jesse Bernard.
} 


\section{O declínio da relevância}

Com o passar do tempo, no entanto, a questão da relevância foi sendo deixada para trás por parte de muitos dos envolvidos no trabalho prático, preterida por uma definição de prioridades muito mais "profissional" e "disciplinar". Desde há já alguns anos que a profissionalização da geração de académicos que sobreveio à década de 1960 constitui tema de discussão, e há pelo menos uma década que se ouve lamentar o desfasamento entre o trabalho levado a cabo pelos "académicos radicais" e as necessidades dos movimentos sociais. Uma boa parte dessa discussão tem-se centrado no florescimento de teorias esotéricas na área da literatura e dos estudos culturais, bem como nos domínios dos estudos sobre as mulheres e da investigação feminista. ${ }^{4}$

Paralelamente, deu-se, a meu ver, um processo idêntico na investigação sobre os movimentos sociais levada a efeito na academia. Abundam os escritos publicados com o intuito de fixar, criticar ou afinar "paradigmas". A maneira mais rápida de aceder a toda essa prolífera produção e de a aferir será examinando a pilha de colectâneas de trabalhos de investigação surgidas nestes últimos anos. Neste preciso momento tenho sobre a minha secretária pelo menos seis volumosas antologias de artigos apostados em apoiar, discutir e contrastar os méritos das perspectivas trazidas pela "mobilização de recursos" (MR), pelos "novos movimentos sociais" (NMS) ou pela "estrutura da oportunidade política" (EOP) (ver Morris e Mueller, 1992; Guigni, McAdam e Tilly, 1999; Guigni, McAdam e Tilly, 1998; Meyer e Tarrow, 1998; Aminzade et al., 2001; McAdam e Snow, 1997; McAdam, McCarthy e Zald, 1996; Goodwin e Jasper, 2004). É cada vez mais forte a sensação de que o trabalho dos investigadores mais jovens é ditado pela sua necessidade de tomar por referência um dos vários "paradigmas” em presença - ou de fazer, de algum modo, a sua síntese. Nos artigos saídos em revistas, é crescente a tendência para aproveitar a análise da experiência dos movimentos sociais para testar hipóteses ou exemplificar conceitos.

Por volta de meados da década de 1980 assistiu-se ao início do surgimento de uma importante quantidade de recensões críticas a que se seguiram diversos compêndios e outros textos contendo investigação pioneira. ${ }^{5}$ Estas obras, todas elas de grande utilidade, ajudaram a codificar o estado desta área de estudo, contudo vieram também reforçar a tendência para o forma-

\footnotetext{
${ }^{4}$ Ver, por exemplo, B. Epstein (1995) e R. Jacoby (1987).

5 Ver C. Jenkins (1983); McAdam, McCarthy e Zald (1988); Morris e Mueller (1992). Para uma explanação abalizada do paradigma primacial, ver Tarrow (1998). A obra Dynamics of Contention constitui uma reapresentação importantíssima da perspectiva fundadora.
} 
lismo. Em 1995, Tilly, McAdam e Tarrow anunciaram estar a envidar esforços muito deliberados e extremamente ambiciosos no sentido de chegar a uma codificação e coordenação de todo o campo. O número de congressos realizados cresceu a um ritmo elevado, e naquele mesmo ano teve início a publicação de uma nova revista, Mobilization, em cujo primeiro número se destacava uma declaração programática da autoria de TMT.

O livro Dynamics of Contention (a mais recente declaração programática de TMT) é essencialmente uma revisão das anteriores propostas de codificação avançadas por estes autores, dando conta de muitas das críticas de que eram alvo. No entanto aí se reafirma também com veemência a defesa do seu papel de liderança no que respeita à definição da área das "políticas de contestação" (ver a recensão crítica contida em Flacks, 2003).

Deste modo, não obstante a proliferação do debate no âmbito dos estudos dos movimentos sociais e as muitas revisões de variados aspectos dos esquemas propostos pelos referidos autores, existe decididamente dentro do campo uma corrente dominante que é definida pelo quadro das "políticas de contestação" tal como é proposto por TMT.

Esta agenda consensual proposta para o campo é considerada um sinal de progresso intelectual relativamente a épocas passadas, em que não parecia existir acordo generalizado quanto à terminologia e em que processos sociais manifestamente semelhantes eram estudados por redes de investigadores com muito pouco contacto entre si.

A superabundância de obras de investigação dedicadas aos movimentos sociais - colectâneas, anuários, revistas, manuais especializados constitui outro indício do referido progresso intelectual. Houve ao longo da última década mais investigação e mais análise sistemática dos movimentos do que nunca, em grande parte com recurso a métodos sofisticados capazes de permitir uma análise histórica e comparativa levada até ao pormenor.

Uma pergunta teimosa persiste, porém: para quê toda esta análise? De que modo é que a validação, o desenvolvimento e a afinação dos conceitos faculta um conhecimento útil para quem busca a transformação social? Será que a prática de uma "ciência normal" colide com a dimensão moral dos estudos dos movimentos sociais?

Poderá parecer que por trás de tais perguntas está uma posição anti-intelectual, ou a tentativa de encontrar um teste simples para a perquisição científica. Contudo as minhas preocupações quanto ao estilo de trabalho hoje em dia prevalecente neste campo prendem-se tanto com o seu valor intelectual como com os seus méritos morais. Como na sua época afirmou Mills, o empirismo abstracto pode parecer ciência, mas esforços desse tipo 
podem acabar por não ser senão exercícios rebuscados destinados a afirmar o óbvio ou o trivial - e, mais provavelmente ainda, exercícios de depuração que confundem mais do que clarificam.

O quadro conceptual prevalecente, tal como surge codificado por TMT e por outros, não é, de facto, uma teoria, ainda que alguns dos seus praticantes tenham por hábito referi-lo como tal. Justifica-se chamar "teoria" a um determinado quadro intelectual quando dele se podem extrair possibilidades para o futuro. Ora isso, a meu ver, é algo surpreendentemente difícil de ser feito com base naquilo que até hoje foi produzido por TMT. Não restam dúvidas de que o "paradigma dominante" nos proporcionou conceitos que ajudam a explicar o passado e nos sensibilizam para questões eventualmente a colocar no decurso da nossa investigação. Nada, portanto, a opor a esse tipo de conceptualização - que de resto se afigura indispensável se quisermos que os estudos dos movimentos sociais sejam algo mais do que um conjunto de narrativas discretas acerca de uma série de acontecimentos históricos.

\section{Os académicos, os activistas, e o identificar das oportunidades políticas}

O esquema dominante fornece-nos um meio conceptual de explicar a "emergência" de vários movimentos, de comparar a dinâmica dos movimentos, e de decidir quais os aspectos a ter em atenção quando penetramos no cenário real de um movimento concreto. Uma coisa que parece incapaz de fazer é permitir uma estimativa prévia dessa emergência e posterior desenvolvimento.

A proposta basilar do modelo TMT original diz respeito à "oportunidade política": os movimentos "emergem" na medida em que quem se encontra numa posição de autoridade não tem condições de os reprimir (devido, por exemplo, a divisões ou instabilidade internas). De uma forma mais geral, "oportunidade política" refere-se a oportunidades de acesso e de mobilização proporcionadas a um dado movimento pelo ambiente político. Esta ideia é especialmente produtiva para a explicação da emergência de movimentos, levando os analistas a não atentar apenas no comportamento e crenças dos participantes nos movimentos, nem nas origens do seu descontentamento, mas a olhar também para a situação das estruturas políticas e das elites já estabelecidas. O problema é só se poder identificar as oportunidades efectivamente relevantes depois do surgimento de um movimento que delas se aproveite (Diani, 2000; Zald, 2000). Dada a falta de especificidade de que as diversas versões do modelo padecem, torna-se muito mais difícil determinar de antemão quais serão as "oportunidades" potenciais de um dado movimento. 
As explicações post facto são um elemento-chave para uma compreensão histórica, no entanto quer parecer-me que as questões mais candentes têm a ver com o futuro. É possível tentar inventariar oportunidades de mobilização plausíveis que eventualmente se revelem relevantes - porém o conceito de "oportunidade política" de pouco serve quando há que decidir que tipos de oportunidade são, de facto, pertinentes para que tipos de esforço de mobilização.

Por definição, os activistas e organizadores que se encontram por trás dos movimentos estão empenhados em esforços no sentido de precaver o futuro, de avaliar as oportunidades e de achar modos de as aproveitar. No entanto, é surpreendentemente raro os estudos históricos que constituem o cânone da abordagem da oportunidade política $(\mathrm{OP})$ centrarem-se nos modos como os activistas dos movimentos analisados entenderam e determinaram as suas próprias oportunidades. $\mathrm{Na}$ verdade, o modo como os organizadores calculam as respectivas oportunidades e como os movimentos as exploram é algo que os praticantes da "OP" deixam por estudar e por teorizar. Os activistas e os organizadores dotados de algum sentido estratégico já sabem que precisam de tentar perceber quais os potenciais pontos de acesso e as possibilidades de alianças existentes num dado ambiente político. No essencial da sua prática cabem os esforços no sentido de avaliar as vulnerabilidades das elites e as suas próprias. É provável que partam do pressuposto de que a estrutura de oportunidades existente não é, efectivamente, propícia aos seus esforços, e por isso vêem-se obrigados a tentar descobrir oportunidades onde estas parecem estar quase totalmente ausentes. É fundamental ver que os organizadores metidos no planeamento e no debate estratégico têm uma maior probabilidade de dominar melhor a natureza da oportunidade política do que os académicos que estão por fora da realidade dos movimentos.

O estudo da oportunidade política dá-nos um exemplo de como os estudos dos movimentos poderiam ganhar um maior ímpeto intelectual se os académicos e os activistas fossem parceiros na teoria e na investigação.

\section{A experiência do activismo}

Outro tópico fértil para uma parceria deste tipo é o problema das "biografias dos activistas”. O estudo das biografias já foi um tópico popular no âmbito dos estudos dos movimentos sociais. ${ }^{6}$ Em resultado disso, existe

\footnotetext{
${ }^{6}$ James Jasper (1997) faz uma crítica muito forte à perspectiva dominante. Jasper apela com veemência ao regresso à "biografia" enquanto tópico-chave para o estudo dos movimentos. No entanto, mesmo este autor parece ignorar, em grande parte, a bibliografia disponível - como por exemplo a referida na nota que se segue.
} 
uma bibliografia relativamente ampla sobre a evolução de activistas individualmente considerados, porém os trabalhos alusivos a este tema foram perdendo aceitação à medida que o paradigma da mobilização de recursos/processo político se foi tornando dominante. ${ }^{7} \mathrm{O}$ estrutural passou, então, a sobrepor-se grandemente ao psico-social na explicação do surgimento dos movimentos sociais.

A viragem estrutural foi crucial no sentido de permitir que os estudos dos movimentos passassem a ver a participação como algo de racional e a actividade como algo de estratégico, e não mais como algo de irracional e meramente "expressivo". Mas tal viragem não implicou necessariamente o alijar da dimensão pessoal dos agentes. De facto, compreender os activistas enquanto tipos sociais continua a ser uma questão crítica para se compreender como funcionam os movimentos sociais. Se se faz sentir a influência dos organizadores, dirigentes, e outros dinamizadores dos movimentos, então a compreensão das respectivas origens sociais, experiência, visão das coisas e motivação pode afigurar-se crítica para a própria compreensão das trajectórias de certos movimentos específicos. Assim, e por exemplo, as origens sociais e os aspectos identitários comuns dos activistas estudantis dos anos 60 ajudam a explicar tanto a ascensão como o declínio do movimento estudantil. ${ }^{8}$

O estudo das biografias dos activistas pode ajudar-nos a responder às perguntas postas por Mill acerca das origens da capacidade humana para buscar a liberdade. Uma das características que definem os activistas é que se trata de pessoas cujos actos se não podem interpretar unicamente em termos de situação; pelo contrário, trata-se de pessoas que agem ao arrepio das expectativas institucionais, das crenças comummente aceites, e dos valores e objectivos convencionais. Por que vias e por que razão hão-de as pessoas envolver-se em actividades arriscadas e não-convencionais, na perspectiva de um "êxito" que é, quando muito, esquivo, e acabando as causas por ser, tantas vezes, perdidas, eis um tópico que, por si só, merece atenção. Como esse empenhamento se consegue manter ao longo dos tempos, é questão que desafia o entendimento geral daquilo que são as possibilidades humanas. De uma relevância fundamental para o problema do potencial democrático é, ainda, a questão de saber por que razão algumas pessoas consideram a

\footnotetext{
7 Eis alguns exemplos: Erikson (1969), Wolfenstein (1967), Keniston (1968). Num livro inteiramente dedicado a indicações bibliográficas, Keniston faz um resumo de centenas de estudos sobre a psicologia social do activismo da década de 1960 (Keniston, 1973). Para uma amostra de trabalhos recentes dentro desta orientação, ver Lipsitz (1995), Andrews (1991), Whalen e Flacks (1989), e Fendrich (1993).

${ }^{8}$ Sobre este tema existe uma abundante literatura produzida na época, incluindo a obra mencionada na nota anterior.
} 
transformação social uma prioridade essencial para as suas vidas. As tentativas de entender as biografias dos activistas podem facultar uma percepção mais aprofundada de certas questões centrais relacionadas com a personalidade humana e a sua socialização, a hegemonia ideológica e as suas contradições, e ainda as relações entre cultura e experiência. O estudo das motivações e da pertinácia do activismo pode, enfim, proporcionar um importante contrapeso e um travão para a dependência excessiva de modelos baseados na escolha racional.

Poder-se-ia supor que a interrogação dos activistas a respeito das respectivas vidas seria vista como uma atitude voyeurista, invasiva, ou de descrédito por parte dos que são objecto de tal investigação. Contudo, a experiência de quantos se têm dedicado a esse trabalho diz que é frequente os activistas mostrarem-se extremamente abertos a este tipo de solicitação. É frequente os organizadores mais experimentados congratularem-se por lhes ser facultada a oportunidade não apenas de contar as suas histórias, mas também de encontrar, assim, sentido no inevitável mistério que são as suas vidas e de as ver num contexto histórico. A oportunidade de reflectirmos sobre as nossas próprias vidas pode ter algo de terapêutico.

Os estudos de natureza biográfica prosseguiram mesmo durante o período em que esse tipo de trabalho se viu, aparentemente, marginalizado. Ao centrar-se nas experiências de vida de diversos organizadores e activistas, algumas obras recentes, de autores como Klatch (1999), Robnett (1997), Teske (1997) e Lichterman (1996), vieram ajudar a compreender em novos moldes as dinâmicas e os resultados dos movimentos. Pode ser que estes esforços, da autoria de jovens investigadores a trabalhar estreitamente com os respectivos "sujeitos" activistas, sejam o prenúncio de um renascimento da ênfase neste género de investigação, aprofundando, assim, os laços entre activistas e académicos.

A tónica do trabalho desenvolvido mais recentemente sobre a experiência do activismo tem recaído menos nas origens do empenhamento dos activistas do que nas suas experiências concretas no interior dos movimentos.

O estudo das origens do empenhamento tem o mérito prático de fazer luz sobre o modo como as pessoas são recrutadas para tal empenhamento, como as perspectivas ideológicas se vão alterando, e como são moldadas as identidades relevantes para os movimentos. Uma outra questão prática foi objecto de pouco estudo no passado: como se consegue manter o empenhamento ao longo dos tempos? O problema pode ser encarado como sendo uma questão de relativamente curto prazo: como manter e incentivar os organizadores e demais pessoal que trabalha a tempo inteiro? como enten- 
der e evitar o desgaste? $\mathrm{O}$ trabalho organizativo desempenhado a tempo inteiro na linha da frente parece exigir graus de disciplina e de sacrifício pessoal que nem sempre se coadunam com as motivações e aspirações dos jovens idealistas que a ele aderem. Começa-se agora a fazer investigação neste domínio sob a égide do movimento operário. Com efeito, um número crescente de cientistas sociais do meio académico tem vindo a orientar o seu trabalho no sentido de aferir muitos aspectos da experiência do activismo no seio do "novo movimento operário" (Bronfenbrenner, 1998; Lopez, 2004; Milkman, 2000). Por norma, este tipo de projectos não tem qualquer articulação com o grosso do trabalho desenvolvido no âmbito dos estudos dos movimentos sociais. Até aqui relativamente marginal enquanto objecto de estudo da investigação sobre os movimentos sociais, o movimento operário proporciona uma espécie de laboratório experimental para observação de um vasto leque de questões relativas à organização de estratégias e tácticas. Além disso, tem havido um esforço activo, da parte de algumas figuras-chave dos novos dirigentes operários a nível nacional, no sentido de cultivar parcerias com académicos.

$\mathrm{Na}$ Califórnia, a Assembleia legislativa estadual financiou, na Universidade da Califórnia, um Instituto do Trabalho e do Emprego que desde há vários anos vem oferecendo quantidades substanciais de bolsas de estudo a docentes e a estudantes pós-graduados, destinadas à investigação de questões relacionadas com o movimento operário. Entretanto, foi recentemente criada uma secção da Associação Americana de Sociologia dedicada aos estudos sobre o novo movimento operário. Estes dois desenvolvimentos, correlacionados entre si, constituem esforços deliberados no sentido de fazer a ponte entre académicos e activistas, fornecendo modelos para a eventual evolução futura de uma parceria desse tipo. No cerne destas iniciativas encontram-se esforços visando aproveitar as experiências e as questões colocadas pelos organizadores, de forma a gerar análises empíricas sistemáticas.

Seria de recear que uma parceria tão estreita - e aquilo que é, praticamente, um patrocínio - tivesse como resultado uma investigação que se limitasse a reforçar os pontos de vista dos dirigentes sindicais. Mas o trabalho já publicado resultante deste tipo de esforços aponta num sentido diferente. Parece implícita, nestes estudos, a ideia de que aquilo de que o sindicalismo necessita é enfrentar a realidade, por mais que isso contrarie pressupostos antigos ou as prerrogativas do passado. A referida investigação contempla um vasto conjunto de preocupações e objectivos: compreender as taxas de êxito de vários tipos de estratégias e métodos organizativos; analisar a resistência dos trabalhadores a certas campanhas; avaliar pro- 
gramas de formação organizacional; estudar alternativas à estrutura sindical operária convencional; ou elaborar relatórios sobre a variabilidade do investimento dos sindicatos nos esforços organizativos. Mais do que oferecer imagens do "progresso" do movimento, o que todo este trabalho sobretudo faz é realçar as limitações, os obstáculos, as lacunas e outros problemas detectados.

A melhor forma de entender a emergente sociologia do movimento operário é vendo como este procura dar sustentação à capacitação colectiva dos trabalhadores, permitindo àqueles que estão seriamente empenhados nesse objectivo dispor de um conhecimento sistemático sobre o modo de o alcançar. Muito deste trabalho pode ser definido como trabalho "aplicado", todavia uma grande parte dele é, ao mesmo tempo e de uma forma mais ampla, relevante para a compreensão das experiências, dos papéis e do potencial dos organizadores em geral.

É óbvio que muitos activistas também se sentem fascinados por aspectos mais básicos da sua experiência. A abordagem biográfica dos activistas pode ajudar a perceber como se consegue manter o empenhamento ao longo de toda uma vida. Esta questão coloca especiais desafios na "pós-modernidade". De facto, não tem hoje cabimento aquela expectativa tradicional que achava que o empenhamento de longo prazo se podia explicar através das convicções ideológicas ou religiosas, e/ou de uma "identidade forte", ou através de particulares qualidades de "coragem" ou "fanatismo". Existem hoje, no entanto, veteranos de movimentos da década de 1960 (eles próprios já quase com sessenta anos!) que continuam a ser organizadores a tempo inteiro ou que prosseguem o seu activismo em projectos variados, apesar de desprovidos dos fundamentos ideológicos (e dos antolhos) que pareciam alicerçar o empenhamento das gerações da velha esquerda. As vicissitudes do empenhamento activista ao longo da vida encontram-se registadas em inúmeros livros de memórias, biografias e romances, parecendo um tema plenamente maduro para a colheita sociológica sistemática - ou seja, uma maneira mais de fazer a ponte entre o activista e o académico.

\section{Em busca da organização democrática}

Doug Bevington e Chris Dixon, estudantes de pós-graduação em sociologia e activistas da Universidade da Califórnia em Santa Cruz, fizeram recentemente um inquérito informal junto de activistas antiglobalização, com vista a fazer um levantamento dos recursos intelectuais e dos discursos teóricos que os norteavam. As conclusões a que chegaram confirmam a crítica que aqui faço: a bibliografia actualmente existente sobre a sociologia dos movimentos sociais não ocupa um lugar prioritário nas listas de 
leitura dos activistas, ao contrário do que sucede com obras como os estudos de caso históricos e contemporâneos, as biografias e os livros de memórias. Mais importante do que isso, no entanto, é o inventário esboçado por Bevington e Dixon da discussão teoricamente relevante disponível em "websites" de activistas e em publicações vocacionadas para a reflexão sobre os movimentos.

Para além de se centrarem em questões relativas à estratégia, à táctica e à construção dos movimentos, estas discussões revelam uma grande preocupação com o modo de assegurar a sua permanente democratização. Eis as principais dimensões dessa preocupação, segundo a perspectiva de Bevington e Dixon:

-O problema da inclusão: como alargar a base social do movimento no que se refere a raça, etnicidade e classe.

-O problema da liderança: como manter a democracia participativa no processo de tomada de decisões do movimento; como superar as clivagens entre os pontos de vista do "activista" e do "quotidiano"; como assegurar que as vozes do movimento se fazem ouvir em toda a sua diversidade.

-O problema da estrutura organizativa: como avaliar os modelos alternativos de organização interna - benefícios e custos comparativos da centralização/descentralização; organização formal vs redes...

Perante este quadro, de imediato se reconhece que os activistas de hoje continuam a debater-se com questões que são centrais para a teoria social dos académicos há pelo menos um século.

Quando Robert Michels explanou a sua teoria da oligarquia organizacional, fê-lo à luz do seu próprio comprometimento com os movimentos que se viviam na época (a Social Democracia alemã). Quando John Dewey, num gesto pioneiro, propôs uma definição de democracia participativa, fê-lo com relação ao papel activo por si desempenhado enquanto dirigente envolvido em actividades socialistas e sindicais durante a década de 1930. Quando William Gamson analisou a relação entre a estrutura organizativa e o êxito dos movimentos, no seu livro Strategy of Social Protest ("Estratégia do protesto social"), fê-lo em resposta ao seu próprio empenhamento nestas questões enquanto participante no movimento contra a guerra do Vietname. Quando Piven e Cloward esmiuçaram de forma crítica os pressupostos e objectivos dos organizadores de movimentos, fizeram-no com base no seu próprio envolvimento activo no movimento pelos direitos à assistência social. 
Numa palavra, uma grande parte do trabalho fundador da teoria social clássica respeitante à problemática das organizações teve a sua raiz na experiência de intelectuais activistas. Esse trabalho continua a constituir um importante recurso para os activistas de hoje. Mas a actual experiência dos movimentos coloca novos desafios relativamente àquilo que era o entendimento de épocas anteriores, e as questões-chave continuam por resolver. Bevington e Dixon instam os sociólogos académicos a embrenhar-se seriamente nos debates que actualmente proliferam entre os activistas da antiglobalização (2003). Não restam dúvidas de que um tal envolvimento pode ser bastante proveitoso, tanto para a causa dos movimentos como para a causa da teoria.

\section{Uma conclusão: recordando Karl Marx}

Karl Marx formulou a teoria singular da estrutura e da dinâmica social mais abrangente de que dispomos. Mas essa obra é claro que não a realizou dentro das paredes da academia. Foi seu objectivo na vida fazer das suas capacidades enquanto intelectual uma fonte de poder para o movimento operário. Os seus primeiros escritos acentuam a ideia de que os desejos emancipatórios dos jovens intelectuais se deveriam fundir com as lutas emancipatórias da classe "agrilhoada". Tais lutas, sabia-o bem, ficariam por cumprir se aqueles que as travavam não fossem capazes de compreender as origens sociais da sua força colectiva, aproveitando desse modo as oportunidades de operar a transformação social.

Dito de outro modo, o modelo de Marx está na base das perspectivas contemporâneas que designamos por mobilização de recursos e estrutura das oportunidades. A exemplo do que sucede com estas perspectivas, Marx compreendeu que a privação e a opressão, só por si, não constituíam alicerce para um movimento. A própria noção de classe como moldura do esforço de mobilização implica que um grupo tem que partilhar recursos e também interesses para se poder tornar uma força social. O estilo "dialéctico" de Marx levou-o a procurar não só os aspectos da opressão mas também as oportunidades inerentes à estrutura social. O capitalismo explora os trabalhadores, mas ao gerá-los gera também os seus próprios coveiros - porque o sistema capitalista, por sua própria natureza, gerou as oportunidades que levarão ao seu próprio derrube (como é, por exemplo, o espaço social proporcionado pela fábrica).

Uma das principais estratégias analíticas de Marx - nomeadamente o esforço para inserir as relações de poder no todo da análise da economia política - encontra-se ausente das teorias contemporâneas. A ideia de oportunidade não devia ser vista como algo de fixo. Quanto mais o capitalismo 
organizasse uma economia e uma sociedade à escala global, maiores as possibilidades de o proletariado de todo o mundo conseguir a mudança transformadora. Uma grande parte do percurso intelectual de Marx foi dedicado ao esforço de analisar o capitalismo como um sistema em desenvolvimento e contraditório, bem como os modos como tal desenvolvimento haveria de, forçosamente, gerar e tornar possível a acção colectiva a partir da base.

A investigação contemporânea na área dos estudos dos movimentos sociais limita-se a estabelecer conexões ténues e relativamente não-sistemáticas entre as condições macro-económicas e a oportunidade política. Assim, e por exemplo, quem pretender (como é o caso de muitos activistas) analisar as oportunidades de revitalização do movimento operário, necessitará de começar por uma análise económica pormenorizada, capaz de estabelecer as conexões entre a "nova economia", as relações de produção existentes (e em vias de evolução) nos níveis macro e micro, e ainda os modos como estas poderão eventualmente impor, viabilizar e restringir a acção colectiva. Na sua resenha da luta pelo encurtamento da semana de trabalho, em O Capital, Marx ofereceu-nos uma análise deste tipo. Surpreendentemente, o "estruturalismo" do paradigma da oportunidade política fica aquém do tipo de análise macro-estrutural que a teorização marxista empreende rotineiramente. ${ }^{9}$

Mas o estruturalismo dos teóricos da oportunidade contém uma debilidade ainda mais básica. Com efeito, estes não lidam de forma sistemática com a possibilidade de certos tipos de recursos e de oportunidades serem bastante mais decisivos do que outros. Para Marx, a grande fonte do poder social passa pelo controlo dos meios de produção. Dado que tal controlo é uma questão de grau, podemos imaginar uma escala de poder à disposição dos grupos que buscam operar a transformação social. Marx avança com a aposta teórica de que, com o tempo, os grupos tenderão a movimentar-se ao longo dessa escala, procurando maximizar o poder de que podem fazer uso. Assim, certas tácticas como por exemplo os comícios de massas, as manifestações, os levantamentos contra a fome, a destruição de maquinaria - todas elas susceptíveis de algum efeito - tornar-se-ão menos importantes para os trabalhadores do que as estratégias centradas na abstenção ao trabalho (como são as greves ou a ameaça delas). As estratégias direccionadas para a greve exigem formas de organização (apostadas em expandir as redes de solidariedade) que em princípio partirão do pressuposto de que, com o

\footnotetext{
${ }_{9}$ Em resposta a esta lacuna intelectual, Buechler (2000) fez uma tentativa sistemática de empreender uma análise deste tipo.
} 
tempo, os trabalhadores apontarão as suas acções colectivas para onde é mais importante. Este tipo de análise sistemática da lógica das relações de poder não o vemos ser feito no projecto da "oportunidade política", inclusivamente por aqueles que se dizem estudiosos do "poder no interior dos movimentos", ou mesmo pelos que se dedicam a documentar os "reportórios tácticos".

A ênfase posta por Marx nas relações de produção enquanto lugar primacial do poder social revelou-se demasiado limitada para uma compreensão cabal da realidade. As lutas de classe não seguiram os rumos por si previstos; entretanto, as tumultuosas conflitualidades sociais acabaram por redesenhar a sociedade e a cultura em função de linhas de fractura que não as do factor classe.

Torna-se, hoje em dia, necessária e possível uma teoria pós-marxista do poder que incorpore a luta de classes mas seja simultaneamente capaz de explicar outros quadros de mobilização e de conflito. Podemos ver um excelente exemplo de uma teoria mais geral do poder numa obra que tem sido menosprezada pelos analistas da "oportunidade política", não obstante adoptar uma perspectiva teórica que parece estar próxima da deles. Trata-se de um livro de Michael Schwartz intitulado Radical Protest and Social Structure ("Protesto radical e estrutura social"), um estudo de 1976 sobre a Southern Farmers Alliance ("Aliança dos Agricultores Sulistas"), do século XIX. Schwartz parte deste estudo de caso para uma reflexão teórica em torno dos factores determinantes dos protestos organizados. $\mathrm{O}$ autor resume deste modo uma reflexão alargada sobre os poderes que os grupos subordinados têm à sua disposição:

Todo o sistema em funcionamento é um conjunto de relações de poder com rotinas próprias, a operar em regime quotidiano. Trata-se de um poder estrutural, uma vez que a estrutura não poderia funcionar sem a existência e sem o uso desse poder. Os $[\ldots]$ que se encontram sujeitos a esse poder estrutural possuem um poder latente, decorrente da possibilidade de se recusarem a acatar o poder que sobre eles é exercido...

Esse poder latente só pode ser exercido se o grupo subordinado se organizar...

A organização do grupo subordinado tem que ser levada a cabo independentemente da própria estrutura...

O poder exercido por um determinado grupo depende do lugar que ocupa na estrutura e da sua capacidade de se abster de obedecer. (Schwartz, 1976: 177)

A proposta de definição de "poder estrutural" de Michael Schwartz ajuda-nos a ver como seria possível construir uma teoria sobre os poderes 
dos mais fracos, a partir da análise do poder de classe feita por Marx: O poder dos despojados radica na sua capacidade de parar o suave fluir da vida social.

Devido ao duplo efeito que tem sobre as elites e a comunidade, o poder de base classista é a maneira mais fácil de o conseguir. Mas toda a estrutura que dependa da cooperação dos subordinados para poder funcionar confere a esses mesmos subordinados um poder potencial, devido à capacidade que têm de se recusarem a cooperar ou de desempenharem os papéis que deles se espera.

Nessa conformidade, pode considerar-se que os movimentos sociais são formações sociais que procuram maximizar, ao longo do tempo, o poder eventualmente disponível para aqueles que representam. Os despojados, ou os "sem poder", têm à sua disposição duas vias para a acção colectiva. Em primeiro lugar, envolver-se ou ameaçar envolver-se em formas colectivas de recusa, de não-cooperação, ou de não-acatamento dos planos, regras, exigências e ordens das elites. Mas como Piven e Cloward demonstraram, na sua análise dos movimentos das populações pobres, as comunidades e grupos mais carenciados podem não ter à sua disposição um poder com capacidade de envolvimento institucional. Em vez disso, os movimentos urbanos dos pobres, desempregados e marginalizados exercem o poder entregando-se a formas colectivas de ruptura do funcionamento normal da vida institucional ou da comunidade (Piven e Cloward, 1979).

Um exercício efectivo do poder baseado no desafio, na ruptura e no incumprimento raramente é fácil, porque os riscos de um tal exercício são, por norma, altíssimos. Tal como as greves de trabalhadores têm custos para esses mesmos trabalhadores (quanto mais não seja, porque é o próprio ganha-pão que assim se vê interrompido), também as outras formas de não-cooperação institucional fazem abalar as actividades de que as pessoas necessitam para manter o ritmo habitual das suas vidas. Além disso, é de esperar que as acções de não-acatamento e de criação de rupturas tenham por resposta a repressão. As dinâmicas dos movimentos sociais são moldadas, em grande parte, pelas tentativas de arranjar maneira de maximizar benefícios e minimizar os custos que a entrada na luta pelo poder acarretará para os membros nela envolvidos.

Vista a esta luz, a actual insistência na ideia de se analisarem as condições de "mobilização" afigura-se abstracta, difusa, e debilmente especificada. Se, em vez disso, considerarmos que o objectivo estratégico subjacente aos movimentos sociais é uma tentativa de encontrar os meios de chegar ao poder estrutural, estaremos em condições de desenvolver formas coerentes 
de imprimir ordem à nossa pesquisa sobre a "oportunidade" e os "recursos". As nossas perguntas sobre estas questões terão que ver com as condições, as circunstâncias, as estratégias e as tácticas, e ainda as percepções e as motivações susceptíveis de aumentar a prontidão de uma dada comunidade ou colectividade de pessoas "sem poder" para que façam uso dos seus poderes estruturais potenciais, geralmente num contexto de escassas probabilidades de êxito. O facto de se ajudar os movimentos a compreenderem o respectivo potencial de poder estrutural permitirá fazer com que o nosso trabalho consiga efectivamente tocar nos dilemas mais profundos com que os organizadores dos movimentos se debatem.

Marx afirmou que a grande questão que se colocava não era apenas compreender o mundo, mas sim transformá-lo. Ao dizê-lo, não pretendeu marginalizar o trabalho intelectual. Muito pelo contrário: construir a teoria é fundamental para se fazer a História, desde que tal construção seja praticada em termos de um diálogo entre os activistas e os académicos.

Tradução de

João Paulo Moreira

\section{Referências Bibliográficas}

Aminzade, Ronald; Goldstone, Jack; McAdam, Doug; Perry, Elizabeth (2001), Silence and Voice in the Study of Contentious Politics. Cambridge; New York: Cambridge University Press.

Andrews, Molly (1991), Lifetimes of Commitment. Cambridge: Cambridge University Press.

Bevington, Douglas; Dixon, Chris (2003), “An Emerging Direction in Social Movement Scholarship: Movement-Relevant Theory”. Comunicação apresentada à Conference on Social Movements and Social Transformation, Cornell University, Março.

Bronfenbrenner, Kate (org.) (1998), Organizing to Win: New Research on Union Strategies. Ithaca; New York: ILR Press.

Buechler, Steven M. (2000), Social Movements in Advanced Capitalism. New York: Oxford University Press.

Diani, Mario (2000), “The Relational Deficit of Ideologically Structured Action”, Mobilization, 5(1), 17-24.

Epstein, Barbara (1995), “Political Correctness' and Collective Powerlessness”, in Marcy Darnovsky; Barbara Epstein; Richard Flacks (orgs.), Cultural Politics and Social Movements. Philadelphia: Temple University Press, 3-19.

Erikson, Erik (1969), Gandhi's Truth. New York: Norton.

Fendrich, James (1993), Ideal Citizens. Albany: SUNY Press. 
Flacks, Richard (2003), "Review of Dynamics of Contention", Social Movement Studies, 2(1), 103-109.

Gamson, William A. (1990), The Strategy of Social Protest (2 ${ }^{\mathrm{a}}$ ed.). Belmont: Wadsworth.

Goodwin, Jeff; Jasper, James. M. (orgs.) (2004), Rethinking Social Movements: Structure, Meaning, and Emotion. Lanham, Md: Rowman \& Littlefield.

Guigni, Marco; Tilly, Charles; McAdam, Doug (orgs.) (1998), From Contention to Democracy. Lanham, Md: Rowman \& Littlefield.

Guigni, Marco; McAdam, Doug; Tilly, Charles (orgs.) (1999), How Social Movements Matter. Minneapolis: University of Minnesota Press.

Jacoby, Russell (1987), The Last Intellectuals. New York: Basic Books.

Jasper, James (1997), The Art of Moral Protest. Chicago: University of Chicago Press.

Jenkins, J. Craig (1983), "Resource Mobilization Theory and the Study of Social Movements”, Annual Review of Sociology, 9, 527-553.

Keniston, Kenneth (1968), Young Radicals. New York: Harcourt, Brace, Jovanovich.

Keniston, Kenneth (1973), Radicals and Militants: An Annotated Bibliography of Empirical Research on Campus Unrest. Lexington, Mass.: Lexington Books.

Klatch, Rebecca (1999), A Generation Divided. Berkeley: University of California Press.

Lichterman, Paul (1996), The Search for Political Community. Cambridge: Cambridge University Press.

Lipsitz, George (1995), A Life in the Struggle (revised edition). Philadelphia: Temple University Press.

Lopez, Steven (2004), Re-Organizing the Rust Belt: From Business Unionism to Social Movement Unionism. Berkeley: University of California Press.

McAdam, Douglas (1999), Political Process and the Development of Black Insurgency, 1930-1970 (2a ed.). Chicago: University of Chicago Press.

McAdam, Douglas; McCarthy, John D.; Zald, Meyer (1988), "Social Movements", in Neil Smelser (org.), Handbook of Sociolog. Newbury Park, CA: Sage.

McAdam, Douglas; McCarthy, John D.; Zald, Mayer (orgs.) (1996), Comparative Perspectives on Social Movements: Political Opportunities, Mobilizing Structures, and Cultural Framings. New York: Cambridge University Press.

McAdam, Doug; Snow, David A. (orgs.) (1997), Social Movements: Readings on their Emergence, Mobilization, and Dynamics. Los Angeles, CA: Roxbury Pub.

McAdam, Douglas; Tarrow, Sidney; Tilly, Charles (2001), The Dynamics of Contention. Cambridge: Cambridge University Press.

Meyer, David; Tarrow, Sidney (1998), The Social Movement Society: Contentious Politics for a New Century. Lanham, Md: Rowman \& Littlefield.

Milkman, Ruth (2000), Organizing Immigrants: The Challenge for Unions in Contemporary California. Ithaca; New York: Cornell University Press. 
Mills, Charles Wright (2000), The Sociological Imagination. New York: Oxford University Press [1959].

Morris, Aldon D.; Mueller, Carol (1992), Frontiers in Social Movement Theory. New Haven: Yale University Press.

Piven, Frances Fox; Cloward, Richard A. (1979), Poor People's Movement. New York: Vintage.

Robnett, Belinda (1997), How Long? How Long? African-American Women in the Struggle for Civil Rights. New York: Oxford University Press.

Ryan, Charlotte (1991), Prime Time Activism: Media Strategies for Grassroots Organizing. Boston: South End Press.

Schwartz, Michael (1976), Radical Protest and Social Structure. New York: Academic Press.

Tarrow, Sidney (1998), Power in Movement (2a ed.). Cambridge: Cambridge University Press.

Teske, Nathan (1997), Political Activists in America: The Identity Construction Model of Political Participation. Cambridge; New York: Cambridge University Press.

Whalen, Jack; Flacks, Richard (1989), Beyond the Barricades. Philadelphia: Temple University Press.

Wolfenstein, Eugene V. (1967), The Revolutionary Personality: Lenin, Trotsky, Gandhi. Princeton, N. J.: Princeton University Press.

Zald, Meyer (2000), "Ideologically Structured Action: An Enlarged Agenda for Social Movement Research”, Mobilization, 5(1), 1-16. 